\title{
VIOLACIÓN DE SECRETOS INDUSTRIALES ANTE LIMITADAS DISPOSICIONES NORMATIVAS EN HONDURAS
}

\section{Carlos Alberto Pérez Madrid ${ }^{1}$}

\section{DOI: https://doi.org/10.5377//rd.v41i1.10500}

\section{RESUMEN}

El objetivo principal de esta exhaustiva investigación, es análisis de una figura jurídica pocamente estudiada en el ámbito legal de Honduras y este es el denominado Secreto Industrial, actualmente con la competitividad tan desmesurada en el mercado internacional y nacional, cada vez se vuelve más utilizada por empresas de diferentes rubros, misma que por su esencia de secreto es muy codiciada para su obtención de manera ilícita, la normativa actual es insuficiente para hacerle frente a estas diversas prácticas de mala fe comercial, ya que la vulneran directamente, a diferencias de otras figuras de la propiedad industrial que cuentan con mecanismos protectorios, esta se le imposibilita utilizarlos ya que las leyes que lo regulan no le otorgan esa tutela, en esta publicación se mostrara directamente como mejorar la protección que tiene el Secreto Industrial en Honduras.

\section{PALABRAS CLAVE:}

Derecho Mercantil, Propiedad Industrial, Secretos Industriales, Violación de Secretos, Competencia Desleal, Espionaje Industrial, Mala Fe Mercantil.

Fecha de recepción:29 de agosto de 2020 Fecha de aprobación: 20 de noviembre de 2020

1 Magister en Derecho Empresarial egresado de la Universidad Tecnología Centroamericana (UNITEC), Asociado de la firma MPF Asesores Legales, encargado del departamento de propiedad industrial, correo electrónico: carlosperezmadrid@hotmail.com. 


\title{
THE VIOLATION OF INDUSTRIAL SECRETS BEFORE THE LIMITED REGULATORY PROVISIONS IN HONDURAS
}

\author{
Carlos Alberto Pérez Madrid ${ }^{2}$ \\ DOI: https://doi.org/10.5377/Ird.v41i1.10500
}

\begin{abstract}
:
The main objective of this article is an analysis of a little-studied legal figure in the legal field of Honduras and this is the so-called Industrial Secret, currently with such disproportionate competitiveness in the international and national market, it is increasingly used by companies of different areas, which due to its essence of secrecy is highly coveted to be obtained illegally, current regulations are insufficient to deal with these various practices of commercial bad faith, since they violate it directly, unlike other figures of industrial property that have protective mechanisms, this makes it impossible to use them since the laws that regulate it do not grant that protection, this publication will show directly how to improve the protection that the Industrial Secret has in Honduras.
\end{abstract}

\section{KEY WORDS:}

Commercial Law, Industrial Property, Industrial Secrets, Violation of Secrets, Unfair Competition, Industrial Espionage, Commercial Bad Faith.

Date received: August 29, 2020 Approval date: November 20, 2020

2 Master in Business Law graduated from the Universidad Tecnología Centroamericana (UNITEC),, Associate of the firm MPF Asesores Legales, in charge of the industrial property department,

Email: carlosperezmadrid@hotmail.com. 


\section{INTRODUCCIÓN}

El secreto industrial como tal es un elemento toral en las sociedades mercantiles modernas, que con el pasar del tiempo se ha tornado de mayor importancia y relevancia en el ámbito del comercio global, el mayor crecimiento del uso de la tecnología por parte de las empresas alrededor del mundo, la globalización, las fluctuaciones de la economía a nivel mundial y la competencia desmesurada en muchas empresas, ha creado que los secretos industriales en pleno siglo XXI, hace que esto se vuelva un foco de mucha atención, ya que el problema radica en eso, la falta de protección y normativa que tiene esta figura en países poco desarrollados.

Esto es un tema que se viene discutiendo por muchos juristas, ya que existen diferentes posturas en el cual se pueden ver las ventajas y desventajas del secreto industrial con relación a una protección que se le puede dar, por ejemplo la protección registral, como lo tienen unas figuras de la propiedad industrial, dígase marcas, emblemas, nombres comerciales, también se puede observar la que se obtiene mediante una patente para proteger una invención, estas posturas no serían de una funcionalidad aplicada para esta figura de estudio, ya que muchos juristas están en total desacuerdo en ello, es esencial que el secreto industrial se guarde sin publicidad alguna, por lógica simple, el secreto que se revela, deja de ser secreto.

Con esto se puede identificar en dónde radica el problema, ya que las principales ventajas del secreto industrial son también sus desventajas esto quiere decir que los secretos industriales frente a otras modalidades de protección son que no conceden un monopolio legal, es decir según la doctrina solo encuentran tutela jurídica frente a la divulgación realizadas por quienes se encuentren implícita o explícitamente sujetos a una obligación de guardar reserva y la pérdida del carácter de secreto puede deberse a un descuido del propio titular.

Por ejemplo, un método de protección que no procedería en todos los casos sería el de una patente.

Estas no permite mantener una ventaja competitiva en materias que no son protegibles eficazmente por otras modalidades teniendo un tiempo límite de protección y además se puede proteger mucha más información con los secretos empresariales que la puede protegerse las patentes, estas últimas solo pueden concederse a innovaciones técnicas nuevas e inventivas, y es importante destacar que el secreto empresarial puede rentabilizarse a través de la concesión de licencias y diversas formas de colaboración" (Perez, 2013).

Como se observa, el campo de estudio de este problema es amplio y de manera analítica, podemos tocar varios puntos importantes, otro objeto de estudio es como va ligado a la competencia desleal, como esto afecta directamente a las empresas, un comportamiento ilícito de ello podemos mencionar al espionaje industrial, esta modalidad se ha multiplicado en los últimos años, casos en la geopolítica mundial.

Un informe de 2017 de la independiente y bipartidista Comisión de EE.UU. menciona sobre el Robo de la Propiedad Intelectual Estadounidense, calculó que el costo anual del robo de propiedad intelectual (PI) asciende a entre \$255 mil millones y $\$ 600$ mil millones en la violación de propiedad industrial. (FU, 2018). 
Por estas razones se ha venido a fortalecer la seguridad jurídica con relación a la protección del Secreto Industrial entre otras figuras de la propiedad industrial a nivel mundial.

\section{METODOLOGÍA}

La metodología de investigación que se utilizó para el presente tema de estudio, es decir la Violación de los Secretos Industriales, para tener un enfoque de investigación acorde, el que se empleo es el cualitativo, ya que este problema de investigación se basa en el derecho este último no trabaja con referentes formales, como las matemáticas y la lógica, por lo que se propone estudiar a fondo la doctrina con las diferentes corrientes de pensamiento, diferente legislación en derecho comparado y jurisprudencia con objeto de sustentar esta investigación, interpretando todo el material disponible, cuyo fin sea, demostrar el cumplimiento de los objetivos de la investigación, también utilizando los diseños más acordes para la elaboración del modelo inductivo del mismo, una definición más amplia de esta metodología seria la siguiente:

Existen ciertas características que identifican la investigación cualita $\neg$ tiva, por una parte, los investigadores centran su interés en acceder a las ex $\neg$ periencias y los datos en su entorno natural de manera que pueda existir un espacio para que se expresen las peculiaridades de las mismas (Herndandez Carrera, 2014, pág. 189).

\section{ANTECEDENTES HISTÓRICOS}

Los secretos han estado estrechamente ligados con el ser humano desde que la existencia de la comunicación, la necesidad de reservar cierta información es parte de la naturaleza humana, evitar que se fugue esta por discreción, temor o compromiso, son de los motivos el cual ha nacido esta figura y se mantiene hoy en día.

La historia de esta figura se remonta hasta los inicios del derecho moderno como hoy lo conocemos, es decir a la antigua Grecia y en la antigua Roma, donde las primereas menciones del secreto como tal fueron creados para un ámbito profesional, es decir como un juramento o solemnidad que debería tener un sujeto en el ejercicio de una profesión por poner un ejemplo: que en Grecia se obligaba a los nuevos médicos a pronunciar el famoso juramento de Hipócrates, el cual decía:

"Todo cuanto, en el trato con los demás, tanto en el ejercicio de la profesión como fuera del mismo, viere u oyere, que no deba divulgarse, lo consideraré absolutamente secreto" (Guillamón, 2011, p.183).

Por otro lado, en la antigua Roma, a los defensores públicos, es decir "a los abogados se les consideraba persona digna e irreprochable, en particular, sirvan como prueba las palabras y el secreto de ella". (Guillamón, 2011, p.184).

Esto iba vinculado a las partes abogado y cliente esto daba a entender que la información entre ellos nunca fuera reveladas a la parte contraria o a terceros ajenos a la relación contractual, es importante mencionar también que en Roma nace la primera pena o mejor dicho acción punible con relación a la divulgación de un secreto, esta pena era de uso exclusivamente para los esclavos, es decir que si un esclavo revelaba algún secreto de su amo se le aplicaba la llamada Pena de Varas. 
Cómo se puede observar, es en el Derecho romano también donde encontramos las primeras referencias a la obligación de secreto, si es cierto que este último iba ligado con el ejercicio de su profesión y tenía similitud al juramento que los médicos hacían en la antigua Grecia, cabe resaltar que esto fue un pilar, para aplicar a futuro el manejo de los Secretos Industriales como normativa.

Al pasar el año se fue creando y consolidando la figura del Secreto Industrial, a principios del siglo XIX,

El primer contacto como tutela jurídica del Secreto Industrial se remonta al periodo napoleónico, fue el Código Civil Napoleónico de 1804 el primero en adoptar sanciones que reprimían la violación de secretos industriales en sus artículos 1,382 y 1,383, además el Código Penal francés de 1810 estableció en su Artículo 418 varios castigos para quienes revelasen secretos industriales, concretamente establecían penas de prisión de dos a cinco años y multas de 500 a 2000 francos para todo director, encargado u obrero de fábrica, que hubiera comunicado o intentado comunicar a extranjeros o a franceses residentes en países extranjeros, secretos de la fábrica de la que fueran empleados (Morales, 2006, p. 83).

\section{SITUACIÓN ACTUAL DEL SECRETO INDUSTRIAL}

La tensión de la fuga de Secretos Industriales se ha puesto la palestra pública en los últimos tiempos por poner ejemplos; podemos analizar la situación de la República Popular de China vs los Estados Unidos de América, involucrados directamente en una guerra comercial que de cierta forma es un conflicto geopolítico la cual se está suscitando entre estas dos potencias de la economía global, la cual ha conllevado a una inmensa fuga de secretos industrial por ambos bandos, que en términos de perdidas pecuniarias el que más se ve afectado en este ámbito son los E.E.U.U.

El robo de información entre Estados empezó con sus programas de armamento nuclear según el Informe Anual del Departamento de Defensa de Los Estados Unidos que Dice lo siguiente:

Las autoridades Norte Americanas, ya avisaban desde años atrás de que el mayor peligro que tenían para su país y sus empresas era el masivo espionaje industrial que tenía el gigantes asiático contra ellos y que tenían que enfocar tanto presupuesto como inteligencia para poder parar estas técnicas desleales de china (America, 2017, pág. 107)

El robo de información sobre armamento bélico, solo fue el inicio, cuando se pudo observar el potencial de esta sustracción de información se podía implementar en un ámbito comercial fue donde empezó a masificarse esta figuras y donde poco a poco la violación de estos secretos industriales se fueron viendo más y más en los países del primero mundo, ya empresas gigantescas sufrían estos problemas, estas sustracciones de información lo que en un primer plano fue como una nueva guerra fría entre dos naciones, se convirtió en una práctica cotidiana en las empresas a nivel mundial, cada día se miraban más situaciones de ese ámbito creando desconfianza entre empresas y exigiendo más seguridad jurídica a sus gobiernos. 
Una de las empresas que más relevancia ha tenido referente al tema es una de las más grandes en la región de las telecomunicaciones a nivel global Huawei, el cual lo hacen responsable de los mayores robos de Secretos Industriales a nivel global en tecnología de telefonía móvil, según se puede avalar con el inicio de procesos judiciales contra "altos directivos de la empresa asiática, se puede mencionar el de la directora financiera de Huawei, Meng Wanzhou, actualmente bajo arresto domiciliario en Canadá, misma que fue enjuiciada en enero del año del 2019, las autoridades de los E.E.U.U”. (Justice, 2020)

El Fiscal Federal de Brooklyn, Richard Donaghue, indicó en la inculpación que Huawei se dedicaba al robo de secretos industriales desde el año 2000, y que en 2013 implementó una política interna que alentaba a sus empleados a robar informaciones confidenciales de rivales con sede u oficinas en este país Norte Americano, en su defensa Huawei se declaró no culpable de los doce cargos iniciales ante un juez federal de Nueva York, En total las acusaciones incluye los dieciséis cargos, en total de cinco compañías están acusadas, todas filiales de Huawei, así como Meng Wanzhou y otros directivos del grupo. (Justice, 2020)

Es necesario recalcar que la problemática de la violación del secreto industrial ha ido incrementando desmesuradamente, países del primer mundo tiene las normativas para apoyarse y poder perseguir estos casos en específicos por poner ejemplo los E.E.U.U, tiene (Defend Trade Secrets Act of 2016) que esta protege directamente a un nivel federal el robo y sustracción de secretos industriales que se den en todo el territorio nacional de este país norte americano, cabe destacar que esta ley es relativamente nueva, como podemos observar es una problemática contemporánea que se está suscitando.

La Organización Mundial del Comercio (OMC) pensó en estos posibles casos con antelación y se creó; el Acuerdo sobre los Aspectos de los Derechos de Propiedad Intelectual relacionados con el Comercio, el cual fue creado en el año 1994 este mismo regulaba en su Artículo 39, la protección de la información no divulgada, es decir los Secretos Industriales y dice textualmente lo siguiente en su numeral dos (2), las personas físicas y jurídicas tendrán la posibilidad de impedir que la información que esté legítimamente bajo su control se divulgue a terceros o sea adquirida o utilizada por terceros sin su consentimiento de manera contraria a los usos comerciales, en la medida en que dicha información:

a) sea secreta en el sentido de que no sea, como cuerpo o en la configuración y reunión precisas de sus componentes, generalmente conocida ni fácilmente accesible para personas introducidas en los círculos en que normalmente se utiliza el tipo de información en cuestión;

b) tenga un valor comercial por ser secreta; $y$

c) haya sido objeto de medidas razonables, en las circunstancias, para mantenerla secreta, tomadas por la persona que legítimamente la controla.

También podemos ver que el entorno tanto social y político se presta a seguir creando estas malas prácticas, siendo parte de la competencia desleal, los países tercermundistas, regiones 
sumamente pobres con economías precarias por poner un ejemplo en Latinoamérica no toman las mismas medidas que los países del primero mundo, por ejemplo para ir a minorizando el enfoque del entorno, parte del continente americano, en este caso América del Sur, todos los países miembros del Mercado Común del Sur (MERCOSUR), No ven al Secreto Industrial, como parte del Derecho de PI, si no como una Situación de Hecho cuartando las malas prácticas como por ejemplo el enriquecimiento indebido por parte de terceros a través de la legislación especiales de Competencia Desleal.

Esto le da un giro diferente al Secreto Industrial, porque no lo protege como una figura más del Derecho de Propiedad Intelectual, como en otros países los vemos, por ejemplo, E.E.U.U, España, y todos los países de Centro América, esto quiere decir que si es cierto que puede llegar a ser un objeto intangible el secreto, se le da una protección directa como un bien mueble tangible de la empresa, ósea esto le puede dar un enfoque diferente, dándole una índole de competencia desleal, es decir las medidas de protección del secreto industrial en estos países de Sur América, son tanto jurídicas como fácticas, ya que se deben de seguir una serie de requisitos para que surta efecto esta protección.

Con los ejemplos de en Sur América y E.E.U.U, medidas que son excepcionales, se puede tener un mejor panorama de la prevención de las violaciones de secretos industriales y que protección se deberá tomar estos ejemplos para efectuar mejoramiento en las normativas que regule el Secreto Industrial en Honduras.

\section{EL SECRETO INDUSTRIAL EN UN SENTIDO AMPLIO, DOCTRINALMENTE HABLANDO}

En sentido amplio se considera Secreto Industrial a todo conocimiento relativo a un proceso de fabricación, estrategia de negocio, desarrollo técnico, producto o servicio que posea una persona natural o jurídica, que se hayan tomado las medidas concretas para ocultarlo, que otorgue una ventaja comercial ante sus competidores y que este garantice un valor pecuniario a su poseedor.

Existen diferentes tipos de conceptos de esta figura legal que se conoce como Secreto Industrial, el cual podemos acuñar los siguientes:

A. Consiste en técnicas o procedimientos industriales descubiertos o creados por una empresa, que no llegan a tener entidad suficiente para ser tutelados mediante una patente de invención, modelo o diseño, pero que permiten a dicha empresa lograr determinada calidad, menores costos o imprimir a sus productos características especiales (Farina, 1993, pág. 259).

B. Conjuntodeconocimientos, información organizada de ellos, que pueden ser transferidos por constar en soportes materiales, que otorga a una empresa ciertas ventajas frente a la competencia o la posibilidad de permanecer en el mercado en situación similar a la de los competidores y se mantiene oculto (Miranda, 1991, pág. 501) 
C. Cualquier información que revista importancia para su propietario, la misma que, por lo general no es de conocimiento público y sobre la cual además el propietario ha tomado todas las medidas del caso para mantener su carácter confidencial y secreto (Gonzalo, 2003, pág. 328)

Se puede observar la diferencia entre conceptos de diferentes juristas con relación a lo que la doctrina define, como secreto industrial, pero se pude concluir que tienen la esencial es que sea de carácter secreto, tenga una aplicación comercial o industrial y que genere una ganancia hacia el propietario, entre otro elemento como la ventaja comercial que tiene sobre sus competidores.

Cabe destacar que también hay juristas que mencionan elementos dentro de la figura que la diferencia más, por ejemplo:

Peña Torres (2001) afirma:

El secreto industrial o trade secret. es toda forma o tipo de información financiera de negocios, científica, técnica, económica o de la ingeniería, que incluya modelos, planos, compilaciones, dispositivos de programas, fórmulas, proyectos, prototipos, métodos, técnicas, procesos, procedimientos, programas o códigos, tangibles o intangibles que hayan sido o no almacenados, compilados o físicamente memorizados en forma electrónica, gráfica, fotográfica o escrita, además de que:

A) el propietario haya adoptado medidas razonables para conservar esa información en secreto.

B) si la información respectiva, independientemente de su valor económico, potencial o actual, no haya sido generalmente conocida y no esté disponible para pasar al domino público. (pág. 414)
El Secreto Industrial es parte directa de la propiedad intelectual que se encuentra individualizado por determinados rasgos como son la heterogeneidad de las informaciones de que trata y la forma en que es protegido, las informaciones objeto de secreto pueden ser de explotación continuada por poner un ejemplo, una información técnico industrial o agotarse en un solo uso el caso de una estrategia publicitaria de mercadeo.

Como la doctrina sitúa esta figura tiene una finalidad muy importante dentro del sector empresarial, en el cual podemos identificar su importancia tan esencial dentro de lo importante que es mantener esa información en secreto, pero que lo hace esencialmente secreto, juristas como José Massaguer Fuentes, tienen un enfoque puntual se lo requisitos fundamentales para que se establezca esta figura de la propiedad intelectual.

Fuentes (2019) nos mencionaba que debe de:

A) ser secreto, en el sentido de que, en su conjunto o en la configuración y reunión precisas de sus componentes, no es generalmente conocido por las personas pertenecientes a los círculos en que normalmente se utilice el tipo de información o conocimiento en cuestión, ni fácilmente accesible para ellas;

B) tener un valor empresarial, ya sea real o potencial, precisamente por ser secreto, $\mathrm{y}$

C) haber sido objeto de medidas razonables por parte de su titular para mantenerlo en secreto (pág. 46). 
Con esta definición doctrinal podemos establecer que el objeto principal del secreto empresarial, es la resguardo de ese bien inmaterial que merece y se determina legalmente como información o conocimiento, que en este contexto constituyen perspectivas de una misma realidad.

Teniendo la suficiente claridad esencial doctrinal de lo que es el Secreto Industrial y el porqué de su funcionamiento, se puede tener una base sólida del sustento de por qué se está elaborando esta investigación, teniendo la opinión de diferentes juristas, tanto de la importancia de su figura como lo es la configuración del mismo, se entrelaza las necesidades básicas, y poder entender la situación actual de esta problemática.

\section{LA PROBLEMÁTICA SOBRE LA NORMATIVA DEL SECRETO INDUSTRIAL EN HONDURAS}

El problema radica directamente en la limitada normativa y protección que se le debe dar a esta figura jurídica conocida como Secreto Industrial, existen varias posturas de el por qué se genera tanta problemática en este tema en específico que deberemos ir visualizando.

Bercovitz (2015) alega que:

Esta problemática va estrechamente ligada a la competencia desleal, el aprovechamiento del esfuerzo de otros, en un primer grupo de supuestos concretos de la competencia desleal es el que caracteriza a esos supuestos porque todos ellos persiguen aprovecharse del esfuerzo de otros participantes en el mercado (pág. 550).
Es decir la falta de protección que tiene a diferencia de una marca, que un registro le otorga Derechos absolutos a un peticionario sobre esa marca, limitando su uso de terceros previo licenciamiento de la misma, de la misma manera pasaría con las invenciones, se los otorga la patente para la protección y evitar la explotación ajena de lo mismo, pero en el caso de los Secretos Industriales la acción de tutela se da hasta la violación de dicho secreto y es ahí donde nace el problema, como se mostró en los antecedentes históricos, este fenómeno se viene repitiendo a través del tiempo y el planteamiento que se debe de hacer es buscar una solución a esta problemática que afecta tanto a empresas tanto de Honduras, como de la región Centro Americana.

Esto no solo se basa en áreas del Derecho Mercantil, Penal y Civil, también está estrechamente relacionado con el Derecho laboral, la falta de cláusulas de confidencialidad y el secreto profesional van ligados, en muchas ocasiones la fuga viene directamente por el descuido de un empleado, no necesariamente es espionaje industrial el que se aplica, es importante también en este punto poder mencionar la aplicación de prácticas de know how, para evitar este tipo de filtraciones.

La problemática principal de la normativa nacional es que carece tanto de definiciones precisas como una protección jurídica amplia que en otros países se puede observar, el principal objeto de esta investigación es de poder tener una tutela acorde a la protección del del Secreto Industrial en pleno siglo XXI. 
La Ley de Propiedad Industrial de la Republica de Honduras, es la norma toral que protege esta figura de estudio en Honduras, como podemos observar, en su Título III, Capitulo Único, en sus artículos, $73,74,75,75,76,77$, podemosencontrarmuchas falencia que tiene esta la norma analizada, la falta de interpretación de lo que es un secreto industrial, ¿cómo se puede proteger algo que no tiene conocimiento de lo que es?, ¿en qué casos se violenta un secreto industrial?, ¿qué mecanismos se puede tener para evitar que se siga violentando?, la doctrina tanto como el derecho comparado se enfoca en mostrar los elementos esenciales de lo que es un secreto industrial es de los principales problemas que se pueden encontrar en la normativa de Honduras.

En base al derecho comparado se tomará de ejemplo principal la normativa española para identificar la falta de protección jurídica que tiene la figura del Secreto Industrial, esta es la llamada, Ley de la Protección de los Secretos Empresariales, publicada el 21 de febrero del año 2019 se tomara un artículo para una mejor comprensión del tema y de la problemática:

Artículo 1. Objeto: A efectos de esta ley, se considera secreto empresarial cualquier información o conocimiento, incluido el tecnológico, científico, industrial, comercial, organizativo o financiero, que reúna las siguientes condiciones:

a) Ser secreto, en el sentido de que, en su conjunto o en la configuración y reunión precisas de sus componentes, no es generalmente conocido por las personas pertenecientes a los círculos en que normalmente se utilice el tipo de información o conocimiento en cuestión, ni fácilmente accesible para ellas;

b) tener un valor empresarial, ya sea realo potencial, precisamente por ser secreto,

c) haber sido objeto de medidas razonables por parte de su titular para mantenerlo en secreto.

2. La protección se dispensa al titular de un secreto empresarial, que es cualquier persona física o jurídica que legítimamente ejerza el control sobre el mismo, y se extiende frente a cualquier modalidad de obtención, utilización o revelación de la información constitutiva de aquél que resulte ilícita o tenga un origen ilícito con arreglo a lo previsto en esta ley.

3. La protección de los secretos empresariales no afectará a la autonomía de los interlocutores sociales o a su derecho a la negociación colectiva, Tampoco podrá restringir la movilidad de los trabajadores; en particular, no podrá servir de base para justificar limitaciones del uso por parte de estos de experiencia y competencias adquiridas honestamente durante el normal transcurso de su carrera profesional o de información que no reúna todos los requisitos del secreto empresarial, ni para imponer en los contratos de trabajo restricciones no previstas legalmente.

A diferencia de Honduras, se tiene un amplio campo de definición, para lo que 
se encarga y lo que debe de proteger, nos establece el objeto esencial de la norma como puede ser detalladamente un Secreto Industrial, que consiste lo que es un secreto, para qué es la finalidad de esta, que nuestra norma menciona pero de manera no tan elaborada jurídicamente, de igual forma deja de manera clara las obtenciones licitas de los denominados secretos, para evitar de igual manera persecuciones legales en casos en específico, también se con relación a los temas laborales, con relación a la manipulación del secreto industrial lo maneja de manera más precisa.

La presente normativa Española entre otros artículos analizados no solo busca prevención directa de una posible violación del secreto industriales si no poder demostrar un daño civil y poder resarcir el daño de la manera más clara posible, el mismos la esencia de los artículos se basa en que infractores de un secreto empresarial podrán ejercitarse las acciones que correspondan cualquiera sea su clase y naturaleza, pudiendo identificar el ilícito esto lo vuelve más fácil de interpretar y resolver.

Entre las acciones civiles que muestra esta norma analizada cabe de destacar la prohibición de la violación ya identificada, ya que de esta manera se puede cesar y evitar seguir teniendo pérdidas directas a la empresa que sufrió la violación del secreto como tal, establece la prohibición directa de fabricación o producción de la materia creada, derivada de la violación del secreto, tanto las importaciones que tenga y exportación del producto, esto conllevando a su inmediato decomiso, esto ayuda directamente en la situación de evitar seguir teniendo perdidas.
La que todo los productos creados por esta violación, se pueden determinar como un lucro cesante, también habla devolución inmediata de todo documento que ligue ese producto creado con el secreto violentado, eso comprende la entrega de la totalidad o parte de los documentos, objetos, materiales, sustancias, ficheros electrónicos y cualesquiera otros soportes que contengan el secreto empresarial, entre otras medias esenciales que deberían tomarse en cuenta para el mejoramiento de la norma que regula esta figura en Honduras es decir la Ley de Propiedad Industrial.

\section{ENFOQUE DE LA NORMATIVA PENAL Y NUEVO CÓDIGO PENAL}

Por otro lado, el enfoque de la normativa penal en Honduras con relación a la Secreto Industrial, en el código vigente se ha enfocado directamente a un solo artículo que regula lo que es el secreto en general, el cual es el siguiente:

Artículo 215. Quien revela sin justa causao emplea en provecho propio o ajeno un secreto del que se ha enterado por razón de su oficio, empleo, profesión o arte y con ello ocasiona perjuicio a alguien, será sancionado con reclusión de tres (3) a seis (6) años.

Se puede observar que una de los principales problemas que podemos observar, no se identifica la figura como Secreto Industrial, si no generaliza el concepto como un secreto en general y que su obtención es un beneficio propio, esto puede ser un problema al momento de aplicar la carga punitiva, ya que la interpretación y las funciones que 
desempeñe el sujeto que cómete el ilícito puede ser expuesto de una manera contraria a la realidad de lo cometido.

Por ejemplo, en España podemos observar diferente el cual se identifica como tal lo que es un secreto empresarial, porque la normativa así lo define, como se puede observar a continuación:

Artículo 279. La difusión, revelación o cesión de un secreto de empresa llevada a cabo por quien tuviere legal o contractualmente obligación de guardar reserva, se castigará con la pena de prisión de dos a cuatro años y multa de doce a veinticuatro meses. Si el secreto se utilizara en provecho propio, las penas se impondrán en su mitad inferior.

Se puede observar cómo ejemplifica y menciona directamente lo que se violentara es un secreto de empresas y dicho ilícito puede ser por mandato legal como en temas contractuales, no solo limitándose a temas empresariales, de igual al comprobar el beneficio propio de estos hechos, podría conllevar a una agravante de la pena, cosa que no vemos en el actual código penal.

El veinticinco (25) de junio del año dos mil veinte (2020) entra en vigencia el nuevo código penal, Decreto 130-2017, en la Republica de Honduras, el cual ha sido gran relevancia nacional, por su cambios punitivos en diversos temas como el narcotráfico, delitos contra el Estado, entre otros y el cual uno de ellos es la figura que estudia esta investigación que es el secreto industrial, el cual se mostrara los artículos los cuales mejoran y amplían el Secreto Industrial.
Artículo 395.descubrimiento y revelación de secreto industrial o comercial: Quien para obtener ilegítimamente un secreto de empresa se apodera por cualquier medio de datos, documentos escritos electrónicos, soportes informáticos u otros objetos que se refieran al mismo, intercepta las comunicaciones o de cualquier otro modo ilegítimo se procura dicha información reservada, debe ser castigado con las penas de prisión de dos.

Se puede observar que el nuevo Código Penal, de manera más completa lo referente con la figura del Secreto Industrial, tanto que identifica directamente lo que es el Secreto Industrial y no lo deja de manera ambigua y general como secreto en sí, establece los medios de cómo pueden ser sustraídos estos secretos, tanto de manera física como de manera telemática, o interceptando medios de comunicación, es en definitiva mucho más completo a lo que la norma actual establece, pudiendo malinterpretarse, cabe señalar que este norma también establece agravante si este violación de secreto se usara en beneficio propio, misma postura podemos verla en el Código Penal Español, se puede observar de donde se obtuvo inspiración el espíritu de la norma y se observa también multa igual o hasta el triple del beneficio obtenido por la violación de ese Secreto.

Cabe destacar que este nuevo Código Penal contara un título exclusivo para los delitos contra la Propiedad Industrial, donde se encuentra el artículo que anteriormente se analizó, entre ellos el uso ilegitimo de patentes, uso ilegitimo de marcas, elusión de medidas tecnológicas e incluyendo la obtención ilegal de Secretos Industriales, la que se enfoca principalmente esta investigación. 


\section{ENFOQUE DE LA NORMATIVA CIVIL}

El Código Civil de Honduras, como tal no define o trata lo que es la figura del Secreto Industrial, pero lo que se enfoca esta norma es en determinar el incumplimiento de las obligaciones, es decir la naturaleza de las obligaciones, la finalidad es determinar la responsabilidad civil, de incumplimiento de una relación contractual, pudiendo aplicarse en diferentes áreas, ejemplo como puede ser un contrato comercial, un contrato de distribución o un contrato de franquicia, el incumplimiento de cláusulas de confidencialidad, y la pérdida de un Secreto Industrial, lo cual es de suma interés ver los artículos siguiente:

Artículo 1359. Toda obligación de no hacer una cosa se resuelve en la de indemnizar los perjuicios.

Artículo 1360. Quedan sujetos a la indemnización de los daños y perjuicios causados los que en el cumplimiento de sus obligaciones incurrieren en dolo, negligencia o morosidad, y los que de cualquier modo contravinieren al tenor de aquellas.

Artículo 1361. La responsabilidad procedente del dolo es exigible en todas las obligaciones. La renuncia de la acción para hacerla efectiva es nula.

Los siguientes artículos no buscan modificar la normativa, más que todo busca identificarla para su correcta aplicación, con relación a la responsabilidad civil, que ocasionaría la violación de un Secreto Industrial, si es cierto que actualmente podríamos iniciar un proceso judicial con la norma que tenemos, sería difícil con los conceptos que tenemos de esta figura, su obtención de manera ilícita y tasar el daño ocasionado, en esta investigación se ha visto en base al derecho comparado, otro países identifican mejor dichos conceptos, aplican elementos más precisos por lo que la determinación de la responsabilidad civil, sería mucho más fácil, tanto en una escenario judicial, como en la aplicación de métodos alternos para la solución de estos conflictos, ya que una vez violentado un secreto industrial, lo que principalmente se buscaría seria resarcir el daño causado.

\section{COMPETENCIA DESLEAL}

Según la doctrina legal, define que la competencia desleal es todo comportamiento que resulte objetivamente contrario a las exigencias de la buena fe mercantil, por lo tanto, toda acción que no se ajusta a las prácticas consideradas como honestas o que pretende alterar su competencia con actos ilícitos o comercialmente incorrectos.

Algunos juristas definen la competencia desleal con ciertas variantes, pero en el fondo guardan la similitud de lo que esta figura establece.

Vicente García (2016) Afirma:

Se entiende por competencia ilícita o desleal todo aquel comportamiento que pueda encuadrarse, usando elementos objetivos de análisis, como contrario a las exigencias de buena fe dentro del plano del comercio con el propósito de incitar la compra de un producto en un enclave determinando afectando negativamente y mermando la libre decisión y elección del comprador. 
Podemos también ver definiciones más dirigidas a los bienes intangibles de una empresa, estos pueden ser enfocados como parte de la propiedad intelectual, por ejemplo, la definición del siguiente jurista.

\section{Becerra Acevedo (2014) Menciona:}

En términos generales se le llama competencia desleal al aprovechamiento que hace un competidor del uso o características distintivas del titular original, como pueden ser las marcas, las patentes, los diseños industriales, o lo que es lo mismo lo que comprende la propiedad industrial en general. (pág. 197)

Con esto se puede se puede corroborar que todo acto contrariamente a la buena fe mercantil, se puede comprender como competencia desleal, cabe de destacar que un elemento que importante de recalcar que para que exista la competencia desleal, se debe de aplicar entre empresas es decir, un acto de competencia desleal no se podría tomar como tal cuando se efectuara por una persona natural, pero existen excepciones a esa regla, claramente pueden haber actos que se utilicen personas naturales para crear ese daño comercial y poder afectar la fama mercantil de una empresa utilizando personas comunes y corrientes, estas pueden ser contratadas por empresas para cometer estos actos contrarios a la buena fe mercantil, por ejemplo, espionaje industrial y sabotaje industrial.

Con esto podemos concluir que la competencia desleal tiene el fin de crear un daño directo a la imagen de una empresa, utilizando diversos medios, con esto podemos decir que la violación de un Secreto Industrial, en efecto sería una práctica de competencia desleal, pero en Honduras, ¿existe una norma que regule esta figura?

Existe una ley, llamada, La Comisión para la Defensa y Promoción de la Competencia Decreto No. 357-2005, misma que se enfoca más en identificar el control de precios, evitar las tarifas restrictivas, o repartición directa o indirectamente el mercado en áreas territoriales, acaparamiento de clientela, sectores de suministro o fuentes comerciales, se enfoca más en evitar en pocas palabras evita la creación de monopolios o oligopolios, si es cierto que estas prácticas se consideraran parte de la mala fe mercantil, indirectamente no lo establece esta norma.

A diferencia de otros países, en este caso España, existe la Ley de Competencia Desleal ley creada en 3/1991, de 10 de enero, esta norma directamente a diferencia de la de Hondura establece que es la violación del Secreto Industrial:

Artículo 13. Violación de secretos. se considera desleal la violación de secretos empresariales, que se regirá por lo dispuesto en la legislación de secretos empresariales.

Artículo 14. Inducción a la infracción contractual.

1. Se considera desleal la inducción a trabajadores, proveedores, clientes $y$ demás obligados, a infringir los deberes contractuales básicos que han contraído con los competidores.

Cabe destacar que la Ley de Propiedad Industrial en su Artículo 170 de la Republica de 
Honduras menciona lo que es la competencia desleal, no habla tan detalladamente de ella, limitándose a un inciso, por ello es evidente que debería de haber una normativa que regulara por si sola como en otros países lo hacen.

\section{ENFOQUE DE LA NORMATIVA LABORAL}

El enfoque principal de la presente investigación no es poder buscar una salida a la normativa laboral, pero si analizar si regula la figura del denominado Secreto Industrial, se debe de empezar estableciendo que la temporalidad de esta norma, es decir el Código del Trabajo de la Republica de Honduras, el año que se creo fue 1959, es decir esta norma tiene aproximadamente sesenta años de existir, a lo que el Secreto Industrial como tal no era algo conocido precisamente, esto se debe a la escasa o minúscula actividad industrial que se llevaba en este país, la actividad económica era hasta cierto punto primigenia.

El actual Código Laboral de la Republica de Honduras, en sus Artículos 97 y 112 no menciona la figura de los Secretos Técnicos, no conocidos como Secretos Industriales en ese entonces, el cual nos hablaba que el trabajador tiene la obligación de proteger dicha información de suma importancia para su patrono y si de dicha manera se violentara el patrono tendría derecho de terminar la relación laboral con el trabajador sin responsabilidad alguna.

De esta forma se puede determinar que el Código Laboral Hondureño emplea como su mecanismo primario, para combatir la fuga de los Secretos Industriales, aplicar estos artículos, no precisos con lo que es la definición moderna de lo que se conoce como Secreto Industrial, pero la ventaja de la normativa es que en el área laboral, existe el reglamento interno del trabajo, este último según la doctrina pertenece o es parte del contrato laboral y su incumplimiento será una causa justa, como causal de despido, claro especificando que y como se da una violación de estos Secretos Industriales y también la aplicación de cláusulas de confidencialidad dentro del contrato dejando claro que como y cuando se violenta un Secreto Industrial, en ambos casos será una falta gravísima y ocasionara su inmediato despido.

Otras salidas que podrían aplicarse de maneras preventivas o medidas coercitivas, seria tomar un enfoque preventivo hacia el empleado, es utilizar clausulas penales en los contratos laborales, aplicando la norma penal ya que la divulgación de Secretos Industriales, es un ilícito penal, que estaría expuesto el trabajador por la revelación de dicha figura, de igual manera la aplicación de cláusulas civil es permisible, con relación a los daños causados, es decir daños y perjuicios.

\section{Mella Méndez (2014) Afirma:}

Al no hallarse previstas expresamente en el Derecho del Trabajo o la inexistencia de una regulación específica en el Derecho del Trabajo obliga a la aplicación supletoria de la normativa civil, dicha normativa será la relativa a la responsabilidad extracontractual o contractual según el daño se produzca durante la fase de los preliminares o tras la celebración de un contrato, a la hora del cálculo de la indemnización se atenderá al criterio del órgano jurisdiccional, diferentes tipos de daños y en su caso, a la existencia de una 
cláusula penal pactada por las partes, la cláusula penal resarcitoria es una estipulación accesoria que las partes añaden a la obligación principal para asegurar su cumplimiento y se hace efectiva cuando el obligado no cumple o lo hace irregularmente su contenido es pecuniario. (pág. 11)

En conclusión, las medidas en el área laboral existen, la figura no es del todo clara, pero los mecanismos en una primera instancia lo que buscarían en un enfoque de esta rama del derecho sería el despido del empleado y los daños colaterales seria aplicables, pero en sus respectivas ramas, como la responsabilidad civil y penal de la violación de los secretos industriales.

Tanto los Estados Unidos de América, España, Chile como todo Mercosur, constan con normas más actualizadas y efectivas para el combate de la violación de esta figura en el cual tomamos de referencia estos países con una vasta experiencia en estos campos de la Propiedad Industrial, para más concreto con los Secretos Industriales para efectuar un análisis comparativo de normas más completo y que tenga un efecto positivo a la finalidad de esta investigación.

\section{CONCLUSIONES}

PRIMERA: La normativa que regula el Secreto Industrial como tal, es decir, la Ley de Propiedad Industrial y en el carácter punitivos el Código Penal, carece de una protección jurídicamente sólida, esta se encuentra en una situación vulnerabilidad para esta figura de estudio, creando vacíos y generando procesos engorrosos y extensos para ejecutar acciones legales contra la violación del llamado Secreto Industrial, principios básicos como el de economía procesal y el de publicidad se ven claramente utilizados en procedimientos del sistemas judicial nacional, estos entran en contradicción con la esencia principal de figura como tal, es decir, lo fundamental de esta figura es evitar su divulgación y es claro que en estas circunstancias no se cumple en ello.

De lo anteriormente mencionado se concluye, la necesidad esencial para la tutela por parte del Estado con relación al Secreto Industrial, sobre la importancia de efectuar las reformas correspondientes de las normas que regulen esta figura, para poder garantizar una seguridad jurídica en un ámbito tanto social como empresarial y fortalecer la economía en general.

SEGUNDO: La falta de conocimiento de los sectores que se ven afectados por la violación del Secreto Industrial, es de los principales fenómenos del presente estudio, ya que cabe resaltar la gran cantidad de desinformación tanto del sector propietario de secretos como la parte tutelar por hacer mención las instituciones que deberían de manejar información de ella por ejemplo la DIGEPIH, esto deja en total evidencia la falta de conocimiento de ambas partes en relación lo que establece la protección de esta figura.

En ese sentido, es de los principales problemas que encontramos es la falta de socialización que tiene el secreto ya que no existen mecanismos de prevención que se encuentre por tanto del Estado como de organizaciones que representen al sector empresarial, este último dado es el ámbito donde más Secretos Industriales podemos 
encontrar, creando desconfianza dentro de los propietarios de los secretos, evitando tanto encontrar asesoría legal institucional y acudiendo con asesoramientos privados, el cual no en todos los escenarios son factibles por los métodos retrógrados que se utilizan para su protección.

TERCERO: Honduras es el país donde se centra esta investigación, donde se observa que los principales problemas que encontramos son la falta de una normativa que garantice mejores mecanismos de respuesta legal para posibles violaciones de los Secretos Industriales, no podemos encontrar de igual manera mecanismos de prevención o sistemas que traten de evitar la filtración de esto secretos, por lo que es una realidad tangible la violación o sustracción ilegal de estos secretos, que tiene una gran afectación tanto en la tutela jurídica como una imagen social y económica como país, ya que no garantiza una prevención correcta ni procesos efectivos y rápidos, para su protección, dejando de manera clara la importancia de aplicar nuevos métodos para la tutela y prevención de cometer actos ilícitos a los poseedores de estas figuras.

\section{BIBLIOGRAFÍA}

America, Department of Defense. (2019). Military and Security Developments. Virginia, Estados Unidos: Office of The Secretary of Defense.

Bercovitz, A. (2015). Propiedad Intelectual.

En Propiedad Intelectual, Temas Relevantes en el Escenario Internacional. Centro América: SIECA, USAID.
Cordero, Z. R. (2009). La Investigación Aplicada: Una Forma de Conocer. Revista Educación. San Jose, Costa Rica: Universidad de Costa Rica.

Fuentes, J. M. (2019). De Nuevo Sobre la Protección Jurídica de los Secretos. Actualidad Jurídica, Madrid, España: Uría Menéndez Abogados, S.L.P. (c/ Príncipe de Vergara, 187, Plaza de Rodrigo Uría, 28002 Madrid. e-mail: alejandro.anca@ uria.com).

U, C. L. (17 de septiembre de 2018). Los Ángeles Times. Obtenido de https:// www.latimes.com/espanol/vidayestilo/ la-es-china-roba-propiedad-intelectualestadounidense-pero-los-aranceles-detrump-podrian-poner-fin-a-la-p-20180917story.html

Farina, J. M. (1993). Contratos Comerciales Modernos, Buenos Aires, Argentina: Editorial Astrea.

Gonzalo, F. D. (2003). Secretos Comerciales y Protección de Información Confidencial. Advocatus, Lima, Peru: El Fondo Editorial de la Universidad de Lima.

Guillamón, C. L. (2011). Aproximación histórico-jurídica al deber de secreto de los abogados en el ejercicio de su profesión. Revista Internacional de Derecho Romano.

Helpdesk, M. I. (2014). Secretos Industriales en Chile. Obtenido de https://www. mercosur.int/: http://www.latinamerica-iprhelpdesk.eu/sites/default/files/factsheets/ es trade secrets in chile imprenta 0.pdf 
Hernandez Carrera, R. M. (2014). La

Investigación Cualitativa Atraves de Entrevistas: Su Analisis Mediante la Teoria Fundamentada. Cuestiones Pedagogicas. Sevilla, España: Universidad De Sevilla.

Justice, D. o. (2020). justice.gov. Obtenido de https://www.justice.gov/opa/pr/chinesetelecommunications-conglomeratehuawei-and-subsidiaries-chargedracketeering

Mella Mendez, L. (2014). La Responsabilidad Civil por Daños en el Contrato de Trabajo. Galicia,

Morales, E. A. (2006). El Secreto Empresarial. Revista del Posgrado en Derecho de la UNAM.

Miranda, R. P. (1991). Méjico: La ley de Fomento y Protección de la Propiedad Industrial de 1991. Revista del Derecho Industrial "Patentes de Invención Cambios Legislativos e Impacto Económico". Buenos Aires, Argentina: Ediciones de Palma.

Peña Torres, M. (2001). "Protección Constitucional del secreto industrial". Revista Chilena de Derecho, Santiago, Chile: Pontificia Universidad Católica de Chile.

Perez, Alvaro. (19 de diciembre de 2013). economia3.com. Recuperado el 2020, de https://economia3. com/2013/12/19/16271-que-es-y-comose-protege-un-secreto-industrial-en- 